\title{
Optimization for Train Schedules of Full-length \& Short-turn Routing Mode in Urban Rail Transit
}

\author{
Yansong Liu ${ }^{1}$, Baohua $\mathrm{Mao}^{2}$, Mengna $\mathrm{Li}^{3}$ \\ ${ }^{1}$ MOE Key Laboratory for Urban Transportation Complex Systems Theory and Technology, Beijing \\ Jiaotong University, Beijing 100044, China \\ ${ }^{2}$ Integrated Transportation Research Centre of China, Beijing Jiaotong University, Beijing 100044, \\ China \\ ${ }^{3}$ Lanzhou Jiaotong University, Lanzhou, China
}

Keywords: Urban rail transit, full-length \& short-turn routing mode, train schedule.

\begin{abstract}
The train schedule is the basis of operation organization in urban rail transit. According to the properties of the full- length \& short- turn routing mode in urban railway transit, a multi- objective nonlinear mixed integer programming optimization model of train shedule for a single transit line is established. The objective functions are minimum passenger travel cost, enterprise operation cost and maximum passenger service level. The constraints of model are set as the shortest headway time interval of consecutive trains, passenger demand and the maximal available electric multiple units. Matlab software can be used to figure out the solution to the multi - objective model based on TOPSIS which can convert the above model into the single objective model. The validity of the model is verified by a case, and positions of turn-back stations are also analyzed. The results indicate that full-length \& short-turn routing mode is better; the shorter length of short - turn routing is not conducive to the passengers, and it cannot lead to a more saving of Operator's cost as well.
\end{abstract}

\section{Introduction}

With the increase of operating mileage, more and more attention is being paid to the reasonable train routing and the train schedule. Due to the uneven distribution of the passenger flow along some urban rail transit lines, single routing is not suitable which will cause that some sections are lack of transport capacity, while other sections are flush of that. In this case, full- length \& short- turn routing mode can not only reduce the turnaround time of trains, and then reduce the passengers' total waiting time, but also reduce the degree of crowding and ensure good service level. So it is very significant to study on how to make train routing scheme for urban rail transit scientifically and reasonably.

From the planning design point of view, the location of the short-turn routing station should be determined according to passenger flow, while the existing research is to fix the position of the station in advance. Moreover, the passenger capacity balance of the section is less considered by previous research. Therefore, in this paper, short routing's origin and terminal stations and train frequencies of long and short train routing will be taken as the decision variables to establish a multiobjective optimization model of train plan about full-length \& short-turn routing mode.

\section{Problem Statement}

\subsection{The Composition of the Line}

The diagram of the full-length \& short-turn routing mode is shown in Fig. 1. We consider how to design an optimal train schedule along one train direction of a two-

Direction rail line, where the stations are sequentially numbered as $s_{1}, s_{2}, S_{3}, \ldots \ldots, S_{n}$. Between the end of line $\left(\mathrm{S}_{1}-s_{n}\right)$, open the full-length train through the whole line. Between the section of large passenger flow $\left(\mathrm{S}_{\mathrm{a}}-S_{b}\right)$, open the short-turn train. For 
Convenience of description, full-length and short-turn routing respectively denoted as $h=1,2$. Train frequencies of long and short train routing are $f_{1}, f_{2}$ respectively.

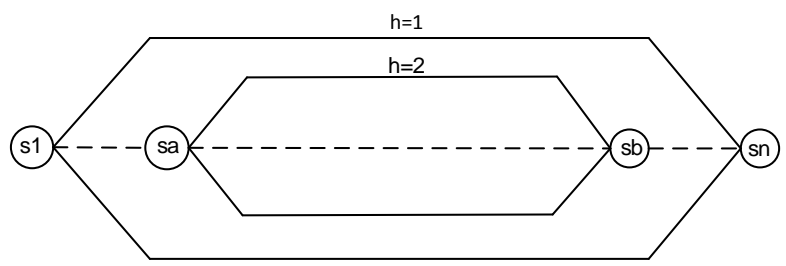

Figure 1. The illustration of full-length and short-turn routing

\subsection{Assumption}

In order to facilitate the establishment of a model, the following assumptions are made.

We assume that the provided total train capacity is greater than or equal to the total passenger demand. This assumption is to ensure that all passengers can be transported to their destination stations during the planning horizon.

Subject in study is linear urban rail transit line and the study period is the morning rush hour.

Train formation plans (full-length and short-turn train) are fixed, and the departure frequency of the short-turn routing is the integer multiple relation of the departure frequency of the full-length routing.

The turnaround mode of rolling stock is used independently for the full-length and short-turn routing.

\section{Optimization Model}

The urban rail transit operation organization involves two main bodies, the supply-side (transport enterprise) and the demand-side (passenger). So the objectives of full-length \& short-turn routing train schedule model are to minimize passenger travel cost and enterprise operation cost.

\subsection{Passenger Travel Cost}

Considering that the train travel speed is the same as that of the single routing, the minimum passenger travel cost can be expressed by the minimum passenger waiting time. Under the condition of short interval, the average waiting time of overall passenger flow approaches half of the interval. As a result, the average waiting time for passengers in the full-length routing section is $30 / f_{1}$, and the average waiting time for passengers in the short-turn routing is $30 /\left(f_{1}+f_{2}\right)$. Due to the departure frequency of the short-turn routing is the integer multiple relation of the departure frequency of the full-length routing, so $f_{2}=k \cdot f_{1}$. Taking the uplink as an example, the total waiting time for different OD pairs $T_{\text {sum }}$ is:

$$
T_{\text {sum }}=T_{1}+T_{2}
$$

The total passenger waiting time at stations in full-length routing section $T_{1}$ is:

$$
T_{1}=\left(\sum_{D=O+1}^{n} \sum_{O=1}^{n-1} q_{O D}-\sum_{D=O+1}^{b} \sum_{O=a}^{b-1} q_{O D}\right) \cdot \frac{1}{2} \cdot \frac{60}{f_{1}}
$$

$q_{O D}$ resembles the cumulative number of arrival passengers at station $\mathrm{O}$ towards station $\mathrm{D}$. The total passenger waiting time at stations in short-turn routing section $T_{2}$ is:

\subsection{Enterprise Operation Cost}

$$
T_{2}=\frac{1}{2} \cdot \frac{60}{f_{1}(1+k)} \cdot \sum_{D=O+1}^{b} \sum_{O=a}^{b-1} q_{O D}
$$

The operating cost of the enterprise related to the train schedule includes two parts: fixed cost and operating variable cost. Fixed cost includes the number of available rolling stock $R_{\text {sum }}$, operating variable cost includes running kilometers of rolling stocks $L_{\text {sum }}$. 


$$
R_{\text {sum }}=\frac{2\left(\sum_{\mathrm{i}=1}^{n-1} t_{y, \mathrm{i}}+\sum_{\mathrm{j}=1}^{\mathrm{n}} t_{s, j}+\sum t_{r}\right)}{60} f_{1}+\frac{2\left(\sum_{\mathrm{i}=a}^{b-1} t_{y, \mathrm{i}}+\sum_{\mathrm{j}=a}^{\mathrm{b}} t_{s, j}+\sum t_{r}^{\prime}\right)}{60} k f_{1}
$$

$t_{y, i}$ is the travel time in i section, $t_{s, j}$ is the stopping time at every station, $t_{r}$ and $t_{r}{ }_{r}^{\prime}$ Are returning time at turn-back stations.

$$
L_{\text {sum }}=\frac{2\left(\sum_{\mathrm{i}=a}^{b-1} \mathrm{t}_{y, i}+\sum_{\mathrm{j}=a}^{\mathrm{b}} t_{s, j}+\sum t_{t^{\prime}}\right)}{60} k f_{1} \cdot \sum_{\mathrm{i}=\mathrm{a}}^{\mathrm{b}-1} \mathrm{~m}_{\mathrm{i}}+\frac{2\left(\sum_{\mathrm{i}=a}^{b-1} \mathrm{t}_{y, i}+\sum_{\mathrm{j}=1}^{\mathrm{n}} t_{s, j}+\sum t_{r}^{\prime}\right)}{60} f_{1} \cdot \sum_{\mathrm{i}=1}^{\mathrm{n}-1} \mathrm{~m}_{\mathrm{i}}
$$

In this function, $m_{i}$ symbolizes the distance of every section.

\subsection{Equilibrium of Train Factor}

In order to improve passenger service level, equilibrium of train load factor is also set as a objective function $U$.

$$
U=\sum_{i=1}^{n-1}\left(u_{i}-\frac{1}{\mathrm{n}-1}\left[\sum_{1<i \leq a-1}\left(\frac{q_{i}}{f_{1} \beta C}\right)+\sum_{a \leq i \leq b-1}\left(\frac{q_{i}}{(k+1) f_{1} \beta C}\right)+\sum_{b \leq i \leq n-1}\left(\frac{q_{i}}{f_{1} \beta C}\right)\right]\right)^{2}
$$

$\beta$ is full-load ratio and $\mathrm{C}$ is the limited number of in-train passengers. $u_{i}$ is train load factor in every section.

\subsection{Equilibrium of Train Factor}

$$
\begin{gathered}
\min z_{1}=T_{\text {sum }} \\
\min z_{2}=w_{1} R_{\text {sum }}+w_{2} L_{\text {sum }} \\
\min z_{3}=U \\
2 \leq \frac{60}{f_{1}(\mathrm{k}+1)}<\frac{60}{f_{1}} \leq 6 \\
\max \left\{\frac{\sum_{D=O+1}^{n} \sum_{O=1}^{n-1} q_{O D}-\sum_{a \leq O \leq b-1} \sum_{O<D \leq b} q_{O D}}{f_{1}}, \frac{\sum_{a \leq O \leq b-1} \sum_{O<D \leq b} q_{O D}}{f_{1}(1+k)}\right\} \leq \beta C \\
s_{1} \leq s_{a} \leq s_{b} \leq s_{n} \\
k \cdot f_{1}+f_{1} \leq f_{\max }
\end{gathered}
$$

(7) (8) are the objective functions, which represents the minimum passenger travel cost and enterprise operation cost. In addition, $w_{2}$ represents operation costs of a train (yuan $\left./ \mathrm{km}\right)$ and $w_{1}$ represents the cost of buying a train (yuan/ train) in (8). (9) (11) are the constraints. (9) Means the interval time is between 2 and 6 minutes. (10) Means train load factor constraint. (12) Means positions of turn-back stations constraint. (12) Means rail capacity constraint, where $f_{\max }$ represents the maximum rail capacity.

\subsection{Algorithm}

The model above is a multi- objective nonlinear mixed integer programming optimization model. It can be solved by TOPSIS which can convert the above model into the single objective model. The ideal point method calculates the distance between the feasible solution set and the ideal solution set, and finds the nearest distance among them to take this feasible solution as the optimal solution.

\section{Case Analysis}

In this chapter, a metro line in a city will be taken as the research object to validate the full- length \& short- turn routing model in this article, and then the optimization results will be analyzed and compared to make an objective evaluation. 


\subsection{Line Condition}

This metro line is $33.9 \mathrm{~km}$ with 23 stations. The average station spacing is $6 \mathrm{~km}$ with the maximum station spacing of $2.41 \mathrm{~km}$ and a minimum station spacing of $0.86 \mathrm{~km}$. Interval passenger flow is shown in Fig. 2, and station spacing and model parameters will be shown respectively in Table I and Table II.

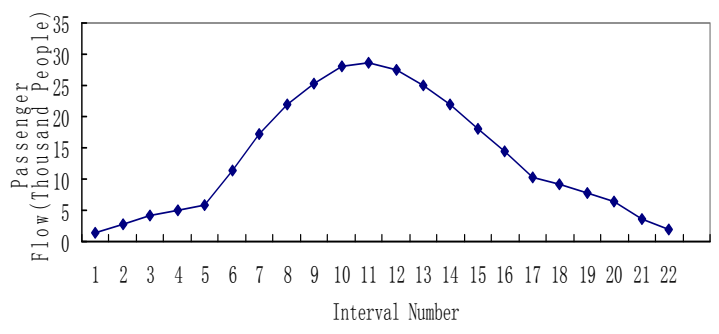

Figure 2. The interval passenger flow curve in peak hour

Table 1. Model parametes

\begin{tabular}{cc}
\hline Parameters & Value \\
\hline The limited number of in-train passengers (person/column) & 1460 \\
load factor & $100 \%$ \\
Train dwell time (s) & 30 \\
Train turn-back time (s) & 120 \\
The maximum rail capacity (column/h) & 30 \\
The minimum frequency (column/h) & 10 \\
\hline
\end{tabular}

Table 2. Station spacing

\begin{tabular}{cccccccccccc}
\hline Interval number & 1 & 2 & 3 & 4 & 5 & 6 & 7 & 8 & 9 & 10 & 11 \\
Staition Spacing (KM) & 1.86 & 1.54 & 1.17 & 1.92 & 2.22 & 1.57 & 1.60 & 1.72 & 1.35 & 1.23 & 0.86 \\
\hline Interval number & 12 & 13 & 14 & 15 & 16 & 17 & 18 & 19 & 20 & 21 & 22 \\
Staition Spacing (KM) & 1.21 & 0.94 & 1.55 & 1.33 & 0.97 & 2.16 & 2.41 & 1.80 & 1.23 & 1.59 & 1.67 \\
\hline
\end{tabular}

\subsection{Results and Options Comparison}

Using Matlab to solve, we can find that the optimal solution is to take $\left[s_{6}, s_{7}\right]$ as the short-turn routing. The concrete result of single routing and the full-length \& short-turn routing mode will be shown in Table 3.

Table 3. Comparison of the results of two models

\begin{tabular}{|c|c|c|c|c|}
\hline Operation time & Model & Turn-back stations & $f_{1}$ & $f_{2}$ \\
\hline \multirow{2}{*}{ Morning peak } & Single routing & - & 21 & - \\
\hline & Full-length \& Short-turn routing & $(6,17)$ & 11 & 11 \\
\hline
\end{tabular}

As shown in TableIV, compared with single routing, Full-length \& Short-turn routing mode makes waiting time, running kilometers of rolling stocks, rolling stock number, equilibrium of passenger load ratio have decreased by $14.6 \%, 37 \%, 22.5 \%$, $45.1 \%$ respectively.

Table 4. Comparison of operational effects between models

\begin{tabular}{ccccc}
\hline Evaluating indicator & Single routing & Full-length \& Short-turn routing & variable quantity & rate of change \\
\hline $\begin{array}{c}\text { Waiting time (minute) } \\
\text { running kilometers of rolling }\end{array}$ & 78560 & 68540 & -10020 & $-14.6 \%$ \\
$\begin{array}{c}\text { stocks (vehicle-km) } \\
\text { rolling stock number (column) } \\
\text { average ratio of passenger } \\
\quad \begin{array}{c}\text { load } \\
\text { Equilibrium of passenger load } \\
\text { ratio }\end{array}\end{array}$ & 2712 & 1710 & -1002 & $-37 \%$ \\
$\quad 2.0357$ & 31 & -9 & $-22.5 \%$ \\
\hline
\end{tabular}




\subsection{Sensitivity Analysis}

Fix other parameters and select different turn-back stations of short-turn routing, and the changing trend of each evaluation index can be shown as TableV. From this Table, when the distance of short-turn routing section decreases, Waiting time will increase, and the shorter the distance the larger increasing ratio. Running kilometers of rolling stocks and rolling stock number will decrease, but the largest decreasing ratio is not at the shortest section. Therefore, for the distance of short-turn routing section, too long or too short will not minimize the benefits of both passengers and businesses.

Table 5. Comparison of operational effects between models

\begin{tabular}{cccccc}
\hline $\begin{array}{c}\text { Station } \\
\text { number }\end{array}$ & positions & $\begin{array}{c}\text { Waiting time } \\
\text { (minute) }\end{array}$ & $\begin{array}{c}\text { running kilometers of rolling } \\
\text { stocks (vehicle-km) }\end{array}$ & $\begin{array}{c}\text { rolling stock number } \\
\text { (column) }\end{array}$ & $\begin{array}{c}\text { Equilibrium of } \\
\text { passenger load ratio }\end{array}$ \\
\hline 10 & $7-16$ & 71360 & 1636 & 30 & 1.469 \\
11 & $6-16$ & 70450 & 1691 & 31 & 1.470 \\
12 & $6-17$ & 68540 & 1710 & 31 & 1.330 \\
13 & $6-18$ & 67350 & 1820 & 33 & 1.342 \\
14 & $6-19$ & 66480 & 1915 & 34 & 1.374 \\
\hline
\end{tabular}

\section{Conclusion}

Under certain passenger flow conditions, the implementation of the Full-length \& Short-turn routing mode can reduce the travel cost of passengers, reduce the number of rolling stocks, reduce the operating costs of transport enterprises and improve Passenger service level. Therefore, when the number of rolling stocks cannot meet the demand of peak passenger flow, it is suggested that transport enterprises should consider the Full-length \& Short-turn routing mode. The shorter length of short- turn routing is not conducive to the passengers, and it cannot lead to a more saving of Operator's cost as well. Therefore, a suitable length is important for Full-length \& Short-turn routing mode.

\section{Acknowledgements}

This research work was financed by National Natural Science Foundation of China (No.71390332), The Fundamental Research Funds of Ministry of Education of China (No.2015JBZ010), National Basic Research Program of China (2012CB725406).

\section{References}

[1]. Yuanyuan Wang. 2013. "Optimization of train schedules of full-length \& short-turn operation modes in urban rail transit,” Railway Operation Technology, 35(7): 1-8.

[2]. Xiang Chen. 2011. "Shanghai Rail Transit Line 11 South Section train combination operation mode,” Railway Operation Technology, 17(2):32-40.

[3]. M. Chen, H. Niu. 2015. "Modeling Transit Scheduling Problem with Short-Turn Strategy for a Congested Public Bus Line,” The Emerging Frontiers of Transportation and Development in China ASCE, pp. 4320-4326.

[4]. Chang Yuhern,Yeh Chunghsing, ShenChingcheng. 2000. "A multi-objective model for passenger train services planning:application to taiwan's high- speed rail line, ” Transportation Research PartB, 34:91-106.

[5]. Xinmao Zhao and Quanxin Sun and Ying Ding.2016. "Passenger Choice Behavior for Regional Rail Transit under Express/Local Operation with Overtaking, ”Journal of Transportation Systems Engineering and Information Technology, 16(5):104-109. 